\title{
Leptin linked to SLE
}

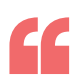

leptin

promoted

effector T cell

responses and

presentation

of self-antigens

to $T$ cells [and]

inhibited ...

$\mathrm{T}_{\text {reg }}$ cells
Leptin promotes both pristaneinduced and spontaneous lupus in mice, according to new findings published in Proceedings of the National Academy of Sciences. "We showed that in mouse models of lupus, leptin could promote unbalanced immune homeostasis through mechanisms that involved a modulation of both effector and regulatory immune circuits," reports Antonio La Cava, corresponding author of the study. "Importantly, we also found that leptin antagonism resulted in the amelioration of disease manifestations and improved immune regulation," he continues.

Intriguingly, patients with systemic lupus erythematosus (SLE) are known to have elevated circulating leptin levels, which suggests that this proinflammatory adipokine might contribute to the sex ratio bias observed in SLE, as circulating levels of leptin are 5-10 times higher in women than in men.

The researchers initially showed that the absence of leptin protected $o b / o b$ mice from pristane-induced lupus (specifically, from development of autoantibodies and renal disease). Pristanetreated $o b / o b$ mice also had an increased frequency of T regulatory $\left(\mathrm{T}_{\mathrm{reg}}\right)$ cells compared with pristane-treated leptin-replete mice. Moreover, in NZB $\times$ NZW mice with spontaneous lupus, leptin levels correlated with disease severity. Administration of leptin to these mice increased the development of autoantibodies and worsened renal disease. "Together, these findings identify new aspects of the pathophysiology of leptin," comments La Cava.

The researchers also showed that leptin promoted effector $\mathrm{T}$ cell responses and presentation of self-antigens to T cells. Furthermore, leptin inhibited both the generation and activity of $\mathrm{T}_{\text {reg }}$ cells.

"Our group has been interested for several years in defining the contribution of leptin to the development and maintenance of autoimmune responses," comments La Cava. He concludes by saying: "We are currently dissecting the mechanisms by which leptin can influence human SLE with the ultimate goal of evaluating the possibility of clinical efficacy of leptin-based approaches in the reduction of proinflammatory responses."

Caroline Barranco

ORIGINAL ARTICLE Lourenço, E. V.et al.

Leptin promotes systemic lupus erythematosus by increasing autoantibody production and inhibiting immune regulation. Proc. Natl Acad. Sci. USA http://dx.doi.org/10.1073/pnas.1607101113 (2016) FURTHER READING Amarilyo, G. et al. Leptin promotes lupus T-cell autoimmunity. Clin. Immunol. 149, 530-533 (2013) 